\title{
PERANCANGAN SISTEM PENGUKURAN KINERJA MENGGUNAKAN METODA PERFORMANCE PRISM
}

\author{
Naniek Utami Handayani, Haryo Santoso, Siti Rochmawati \\ Industrial Engineering Department, Diponegoro University \\ Jl. Prof. Sudarto, SH, Tembalang, Semarang \\ Phone/Fax.024-7460052 E-mail: naniekh@yahoo.com
}

\begin{abstract}
$X Y Z$ company is a printing and publishing company, especially for lesson and education books with more than 50 branch offices in Indonesia. As a profit oriented organization, so far performance measures of this company only based on financial aspect. Whereas, non financial aspect and stakeholder wants and needs ignored and didn't get enough attention. So, it is difficult to know overall company performance exactly. Therefore, required new performance measurement system that can describe company performance more comprehensive and integrated. This research use performance prism method to design the new performance measurement system because it is more suitable and representative with the objective condition of $X Y Z$ company than other models.

The result of design describe that stakeholders of $X Y Z$ company are including: customers, employees, investors and owners, suppliers, regulators and local communities. Measurement system obtained $31 \mathrm{Key}$ Performance Indicators(KPI) including 3 KPI of customers, 9 KPI of general employees, 4 KPI of production employees, 7 KPI of investor and owners, 3 KPI of suppliers, and 5 KPI of regulators and local communities. Result of implementation performance measurement system with scoring system using OMAX method indicates that amount of scor current performance indicator is $69 \%$. From overall KPI, these are 4 KPI with bad performance criteria, that is amount of customer's complaint, amount of eployee's complaint with completion, increase of production volume and amount of late delivery of employee's monthly report. Result of measurement can be based for doing evaluation and choice planning improvement organization, so all stakeholder requirements can be fulfilled.
\end{abstract}

Keywords : Performance Prism, performance measurement, stakeholder

\section{PENDAHULUAN}

Perusahaan XYZ merupakan perusahaan yang bergerak di bidang penerbitan dan percetakan buku, terutama buku-buku pelajaran dengan lebih dari 50 kantor cabang di seluruh Indonesia. Disamping Perusahaan XYZ, saat ini ada empat penerbit besar yang menguasai pasar buku-buku pelajaran sekolah di Indonesia, yaitu Erlangga, Yudhistira, Intan Pariwara dan Tiga Serangkai. Dengan semakin meningkatnya persaingan tersebut, menjadikan perusahaan harus mampu menerapkan strategi yang tepat di semua lini agar dapat memenuhi keinginan stakeholders. Sebagai organisasi yang berorientasi pada keuntungan (profit oriented), selama ini ukuran kinerja Perusahaan XYZ hanya didasarkan pada aspek finansial menggunakan rasio profitabilitas. Sistem pengukuran kinerja tersebut dianggap belum mampu memotret kinerja perusahaan secara keseluruhan 
sehingga pihak manajemen mulai menyadari perlunya melakukan perancangan sistem pengukuran kinerja yang baru dengan memperhatikan aspek finansial dan non finansial.

Saat ini, ada tiga model sistem pengukuran kinerja terintegrasi yang populer dan digunakan secara luas di dunia industri yaitu: Balanced Scorecard dari Harvard Business School [7], Integrated Performance Measurement System (IPMS) dari Centre for Strategic Manufacturing University of Strathclyde, dan Performance Prism dari kolaborasi antara Accenture dengan Cranfield School of Management (Cambridge University) [3].

Pada penelitian ini, peneliti menggunakan metoda Performance Prism karena memiliki keunggulan dibanding dua metoda yang lain. Bila dibandingkan dengan Balanced Scorecard, Performance Prism memiliki beberapa kelebihan diantaranya mengidentifikasi stakeholder dari banyak pihak yang berkepentingan, seperti pemilik dan investor, supplier, pelanggan, tenaga kerja, pemerintah dan masyarakat sekitar. Sedangkan Balanced Scorecard mengidentifikasikan stakeholder hanya dari sisi shareholder dan customer saja. Bila dibandingkan dengan IPMS, Performance Prism memiliki kelebihan, yaitu Key Performance Indicator (KPI) yang diidentifikasi terdiri dari KPI strategi, KPI proses, dan KPI kapabilitas. Sebaliknya, IPMS langsung mengidentifikasikan KPI-KPInya tanpa memandang mana yang merupakan strategi, proses, dan kapabilitas perusahaan.

Di sisi lain, ada keinginan dari obyek penelitian, agar sistem pengukuran kinerja memperhatikan aspek kepuasan stakeholder secara komprehensif, yakni menyertakan kepentingan semua stakeholder yang terkait serta kepentingan perusahaan yang bersangkutan. Didasarkan atas keunggulan dan tujuan perusahaan, maka perancangan dan implementasi sistem pengukuran kinerja pada Perusahaan XYZ akan menggunakan model Performance Prism.

Selama ini, pengukuran kinerja perusahaan hanya didasarkan pada aspek finansial saja, yaitu dari rasio profitabilitas yang secara otomatis hanya memenuhi keinginan satu stakeholder saja, yakni pemilik dan investor. Sedangkan aspek-aspek non finansial dan keinginan dari stakeholders yang lain seperti terabaikan dan kurang mendapatkan perhatian. Sehingga, kinerja perusahaan secara keseluruhan tidak diketahui secara pasti. Oleh karena itu, diperlukan sistem pengukuran kinerja yang baru yang mampu memotret kinerja perusahaan secara lebih komprehensif dan integratif.

Adapun tujuan dari penelitian ini adalah:

a. Mengidentifikasi kepuasan dan keinginan sekaligus kontribusi para stakeholder Perusahaan XYZ

b. Mengidentifikasi strategi, proses dan kapabilitas perusahaan untuk memenuhi kepuasan dan kontribusi stakeholder.

c. Mengidentifikasi Key Performance Indicators (KPI).

d. Mengukur kinerja perusahaan berdasarkan hasil rancangan yang telah ditetapkan sebelumnya.

e. Memberikan usulan perbaikan kinerja pada perusahaan dan prioritasnya setelah hasil implementasi didapatkan dan dievaluasi. 


\section{METODA PENELITIAN}

Performance Prism merupakan model yang berupaya melakukan penyempurnaan terhadap metoda sebelumnya seperti Balanced Scorecard dan IPMS. Performance Prism merupakan suatu metoda pengukuran kinerja yang menggambarkan kinerja organisasi sebagai bangun 3 dimensi yang memiliki 5 bidang sisi, yaitu dari sisi kepuasan stakeholder, strategi, proses, kapabilitas, dan kontribusi stakeholder [5].

Performance Prism mempunyai pandangan yang lebih komprehensif terhadap stakeholders (seperti investor, pelanggan, karyawan, peraturan pemerintah dan supplier) dibanding kerangka kerja lainnya [5]. berpendapat bahwa kepercayaan umum yang meyakini bahwa ukuran kinerja harus diturunkan secara ketat dari strategi adalah tidak benar. Seharusnya, kebutuhan dan keinginan dari para stakeholders-lah yang harus diperhatikan pertama kali. Kemudian, baru strategi dapat diformulasikan.

Performance Prism berpendapat bahwa sebuah sistem pengukuran kinerja seharusnya diorganisir dalam lima perspektif kinerja yang berbeda namun saling berkaitan, yakni:

a. Kepuasan Stakeholder

Siapa saja stakeholder organisasi dan apa saja keinginan dan kebutuhan mereka? Stakeholder yang dipertimbangkan di sini meliputi konsumen, tenaga kerja, supplier, pemilik/investor, serta pemerintah dan masyarakat sekitar. Penting bagi perusahaan berupaya memberikan kepuasan terhadap apa yang diinginkan dan dibutuhkan stakeholder-nya serta melakukan komunikasi yang baik dengan mereka.

Strategi

Strategi apa yang dibutuhkan untuk memberikan kepuasan terhadap keinginan dan kebutuhan para stakeholder? Strategi dalam hal ini sangat diperlukan untuk mengukur kinerja organisasi sebab dapat dijadikan sebagai monitor (acuan) sudah sejauh mana tujuan organisasi telah dicapai, sehingga pihak manajemen bisa mengambil langkah cepat dan tepat dalam membuat keputusan untuk menyempurnakan kinerja organisasi.

b. Proses

Proses-proses apa saja yang dibutuhkan untuk meraih strategi yang sudah ditetapkan? Proses di sini diibaratkan sebagai mesin dalam meraih sukses: yaitu bagaimana caranya agar organisasi mampu memperoleh pendapatan yang tinggi dengan pengeluaran serendah mungkin melalui pemampatan fasilitas serta pengoptimalan saluran-saluran pengadaan (procurement) dan logistik.

Kapabilitas

Kemampuan-kemampuan apa saja yang dibutuhkan untuk menjalankan proses yang ada? Kapabilitas atau kemampuan di sini maksudnya adalah kemampuan yang dimiliki oleh organisasi meliputi keahlian sumber dayanya, praktek-praktek bisnisnya, pemanfaatan teknologi, serta fasilitasfasilitas pendukungnya. Kemampuan organisasi ini merupakan pondasi 
yang paling dasar yang harus dimiliki oleh organisasi untuk dapat bersaing dengan organisasi-organisasi lainnya.

c. Kontribusi Stakeholder

Kontribusi apa yang kita butuh dan kita inginkan dari para stakeholder untuk mengembangkan kemampuan yang kita miliki? Untuk menentukan apa saja yang harus diukur yang merupakan tujuan akhir pengukuran kinerja dengan metoda Performance Prism ini, maka organisasi harus mempertimbangkan hal-hal apa saja diinginkan dan dibutuhkan dari para stakeholdernya. Sebab organisasi dikatakan memiliki kinerja yang baik jika mampu menyampaikan apa yang diinginkannya dari para stakeholder yang sangat mempengaruhi kelangsungan hidup organisasi mereka.

Gambar 1 sampai 3 menunjukkan bahwa masing-masing bidang sisi prisma memiliki hubungan satu sama lain dalam merepresentasikan kunci sukses atau tidaknya kinerja suatu organisasi.

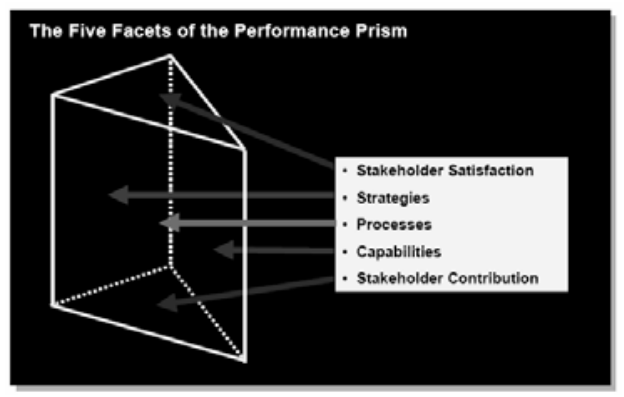

Gambar 1. Sudut Pandang Performance Prism [5]

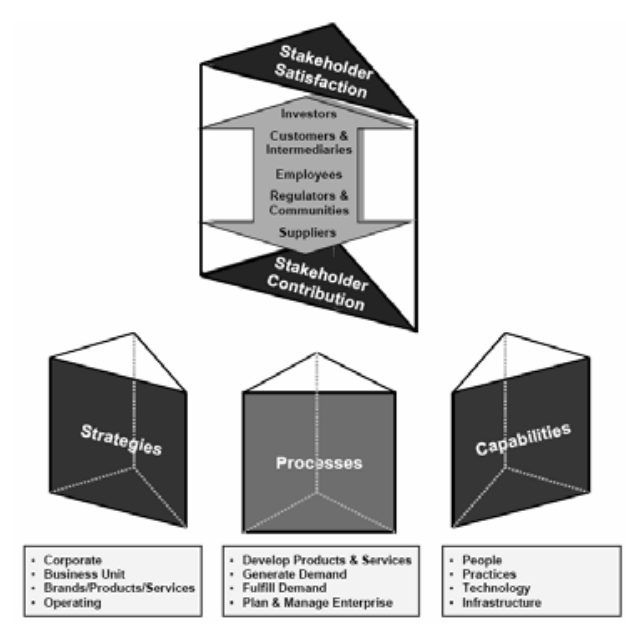

Gambar 2 Ruang lingkup Model Performance Prism [5]

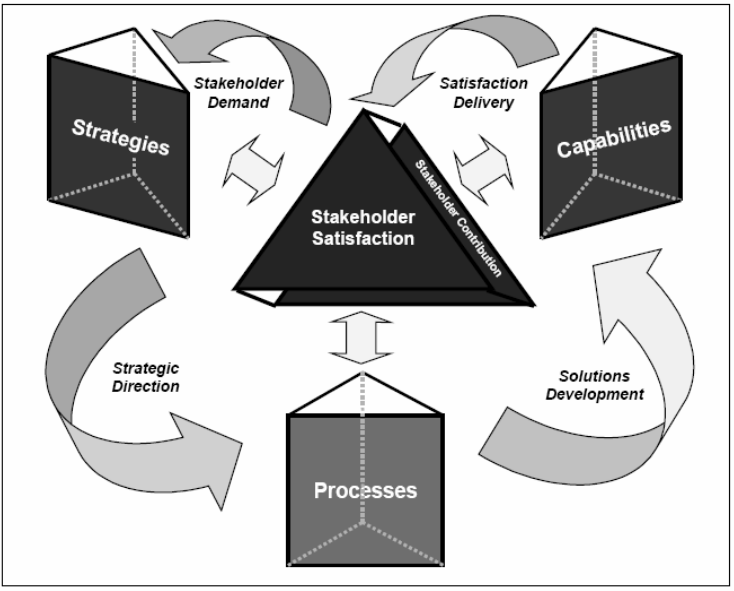

Gambar 3 Hubungan Keterkaitan Kelima Segi dalam Performance Prism [6] 


\section{HASIL DAN PEMBAHASAN}

Berdasarkan hasil pengukuran kinerja yang telah dilakukan, maka dapat dilakukan analisis sebagai berikut:

\subsection{Stakeholder Pelanggan}

Hasil pengukuran kinerja pada stakeholder pelanggan menunjukkan pencapaian kinerja dengan kriteria sedang dengan jumlah nilai pengukuran 2.02 dari total keseluruhan bobot untuk 3 KPI. Adapun rinciannya adalah sebagai berikut:
a. KPI dengan kriteria baik meliputi:
- Prosentase pertumbuhan jumlah pelanggan (KPI 1)
- Rasio jumlah keluhan terlayani (KPI 3)
b. KPI dengan kriteria sedang tidak ada.
c. KPI dengan kriteria buruk adalah KPI 2, yaitu jumlah keluhan pelanggan.

\subsection{Stakeholder Karyawan}

Hasil pengukuran kinerja pada stakeholder karyawan menunjukkan pencapaian kinerja dengan kriteria sedang dengan jumlah nilai pengukuran 2.79 dari total keseluruhan bobot untuk 13 KPI.

\subsubsection{Karyawan secara Umum}

Hasil pengukuran nilai performansi karyawan secara umum menunjukkan pencapaian kinerja dengan kriteria sedang dengan jumlah nilai pengukuran 2.15 untuk 9 KPI. Adapun rinciannya adalah sebagai berikut:

a. KPI dengan kriteria baik meliputi:

- Jumlah reward yang diberikan (KPI 4)

- Prosentase absensi karyawan (KPI 6)

- Jumlah karyawan yang terkena sanksi (KPI 7)

- Tingkat kecelakaan kerja (KPI 11)

b. KPI dengan kriteria sedang ada 4 buah. Tabel 1 memberikan analisisnya.

c. KPI dengan kriteria buruk adalah KPI 12, yaitu jumlah keluhan karyawan yang diselesaikan

\subsubsection{Karyawan bagian produksi}

Hasil pengukuran nilai performansi karyawan di bagian produksi menunjukkan pencapaian kinerja dengan kriteria sedang dengan jumlah nilai pengukuran 0.64 untuk 4 KPI. Adapun rinciannya adalah sebagai berikut:

a. KPI dengan kriteria baik meliputi:

- Rasio breakdown mesin (KPI 15)

- Rasio demerit point (KPI 16)

b. KPI dengan kriteria sedang adalah KPI 5, yaitu tingkat produktivitas karyawan.

c. KPI dengan kriteria buruk adalah KPI 14, yaitu peningkatan volume produksi. 


\subsubsection{Stakeholder Pemilik Modal}

Hasil pengukuran kinerja pada stakeholder pemilik modal menunjukkan pencapaian kinerja dengan kriteria baik dengan jumlah nilai pengukuran 1.14 dari total keseluruhan bobot untuk 7 KPI. Adapun rinciannya adalah sebagai berikut:

Tabel 1. Analisis Kinerja Stakeholder karyawan secara umum dengan kriteria sedang

\begin{tabular}{|c|c|c|c|}
\hline KPI & Jenis KPI & Analisis & Rekomendasi \\
\hline 8 & $\begin{array}{l}\text { Rasio } \\
\text { komputer } \\
\text { yang tersedia }\end{array}$ & $\begin{array}{l}\text { Rasio komputer yang ada belum } \\
\text { sebanding dengan jumlah staff yang } \\
\text { menggunakannya. Seringkali } 1 \\
\text { komputer harus digunakan oleh } \\
\text { beberapa orang sehingga banyak } \\
\text { pekerjaan yang menumpuk. }\end{array}$ & $\begin{array}{ll}\text { Menambah jumlah } & \text { komputer } \\
\text { sehingga jumlahnya } & \text { sebanding } \\
\text { dengan beban pekerjaan di setiap } \\
\text { bagian atau divisi. }\end{array}$ \\
\hline 9 & $\begin{array}{l}\text { Jumlah } \\
\text { training } \\
\text { program yang } \\
\text { diberikan }\end{array}$ & $\begin{array}{l}\text { Pelaksanaan training tidak sesuai } \\
\text { dengan yang dijadwalkan karena } \\
\text { perusahaan kesulitan mengalokasikan } \\
\text { waktu ditengah kesibukan proses } \\
\text { produksi. }\end{array}$ & $\begin{array}{l}\text { Evaluasi kembali penjadwalan } \\
\text { training yang akan disesuaikan } \\
\text { dengan jadwal produksi dan tingkat } \\
\text { kebutuhan karyawan }\end{array}$ \\
\hline 10 & $\begin{array}{l}\text { Jumlah } \\
\text { karyawan } \\
\text { yang } \\
\text { memakai } \\
\text { jamsostek }\end{array}$ & $\begin{array}{l}\text { Hanya sebagian dari karyawan tetap } \\
\text { saja yang memakai jamsostek, } \\
\text { sedangkan sebagian yang lain dan } \\
\text { karyawan kontrak tidak. }\end{array}$ & $\begin{array}{l}\text { Perusahaan hendaknya memberikan } \\
\text { jamsostek kepada semua karyawan } \\
\text { tetap dan memberikan jaminan sosial } \\
\text { yang sejenis untuk karyawan kontrak } \\
\text { selama dia bekerja disana. }\end{array}$ \\
\hline 13 & $\begin{array}{l}\text { Kepuasan } \\
\text { kerja } \\
\text { karyawan }\end{array}$ & $\begin{array}{l}\text { - Kurangnya perhatian dari pimpinan } \\
\text { - Jenjang karir tidak jelas } \\
\text { - Jenuh dengan pekerjaan } \\
\text { - Gaji dan insentif yang kurang } \\
\text { sebanding dengan hasil kerja }\end{array}$ & $\begin{array}{l}\text { - Pimpinan lebih memperhatikan } \\
\text { keluhan karyawan } \\
\text { - Penghargaan bagi karyawan yang } \\
\text { kurang berprestasi baik berupa } \\
\text { bonus atau kenaikan jabatan dan } \\
\text { sanksi untuk karyawan yang tidak } \\
\text { disiplin. } \\
\text { - Menyediakan waktu untuk rekreasi } \\
\text { bersama } \\
\text { - Evaluasi terhadap sistem gaji dan } \\
\text { insentif terhadap karyawan }\end{array}$ \\
\hline
\end{tabular}

a. KPI dengan kriteria baik meliputi:

- Prosentase Total Sales Growth (KPI 17)

- Tingkat perputaran aset total (KPI 18)

- Prosentase Net Profit Margin (KPI 19)

- ROE (Return On Equity) (KPI 21)

- Quick ratio (KPI 22)

- Current ratio (KPI 23)

b. KPI dengan kriteria sedang adalah KPI 20, yaitu Return of Investment (ROI).

c. KPI dengan kriteria buruk tidak ada.

\subsubsection{Stakeholder Supplier}

Hasil pengukuran kinerja pada stakeholder supplier menunjukkan pencapaian kinerja dengan kriteria baik dengan jumlah nilai pengukuran 0.64 dari total 
keseluruhan bobot untuk 8 KPI. Dari ketiga KPI tersebut, semuanya sudah mencapai kriteria baik sehingga tidak memerlukan tindakan perbaikan yang berarti.

\subsubsection{Stakeholder Pemerintah dan Masyarakat Setempat}

Hasil pengukuran kinerja pada stakeholder pemerintah dan masyarakat setempat menunjukkan pencapaian kinerja dengan kriteria baik dengan jumlah nilai pengukuran 0.31 dari total keseluruhan bobot untuk 5 KPI. Adapun rinciannya adalah sebagai berikut:

a. KPI dengan kriteria baik meliputi:

- Jumlah keterlambatan pembaharuan ijin lingkungan dan industri

- Jumlah program sosial keagamaan yang dilaksanakan

- Jumlah tenaga kerja lokal yang terserap

- Jumlah siswa/i dan mahasiswa/i yang kerja praktek/magang dan penelitian

b. KPI dengan kriteria sedang tidak ada.

c. KPI dengan kriteria buruk adalah KPI 26, yaitu jumlah keterlambatan pelaporan aktivitas ketenagakerjaan.

Secara keseluruhan, nilai pencapaian kinerja Perusahaan XYZ pada tahun 2004 adalah sebesar 69\% dari yang telah ditargetkan.

Dari evaluasi tersebut, ada beberapa rekomendasi perbaikan untuk KPI-KPI dengan kriteria buruk dimana perusahaan harus cepat mengambil tindakan untuk memperbaiki kinerja indikator-indikator tersebut:

a. Tingginya jumlah keluhan pelanggan dapat dimimalkan dengan melakukan usaha-usaha sebagai berikut:

- Membina hubungan baik dengan pelanggan, dengan mengoptimalkan sarana komunikasi dengan pelanggan, seperti suara pelanggan, sarana komplain, dll.

- Mengadakan survei kepuasan pelanggan secara rutin.

- Memperketat proses Quality Control, baik ditingkat produksi maupun pada saat memberikan pelayanan kepada pelanggan

b. Rendahnya jumlah keluhan karyawan yang dapat diselesaikan oleh pihak perusahaan dengan mengoptimalkan sarana-sarana yang menjembatani komunikasi karyawan, seperti suara karyawan, kotak saran, fungsi pengawasan dari tiap supervisi, ramah tamah dan rekreasi karyawan dengan pimpinan, dalam waktu-waktu tertentu, pimpinan perusahaan juga dapat turun langsung ke lantai produksi untuk mengetahui kondisi kerja disana dan menjalin komunikasi dengan karyawan.

c. Peningkatan volume produksi yang tidak sesuai target dapat diantisipasi perusahaan dengan perancangan sistem perencanaan produksi yang baik dan strategi yang tepat untuk melaksanakannya. Target-target produksi sedapat mungkin disosialisasikan kepada karyawan sehingga mereka mengetahui target kerja mereka sekaligus merasa dilibatkan dalam pencapaian target tersebut. 
d. Sering terjadinya keterlambatan dalam penyerahan laporan bulanan aktivitas ketenagakerjaan ke Disnakertrans dapat diantisipasi dengan membuat dokumentasi sistem data dan informasi perusahaan yang baik.

\section{SIMPULAN}

Dari proses perancangan sistem pengukuran kinerja dan implementasinya menggunakan metoda Performance Prism di Perusahaan XYZ, dapat diambil kesimpulan sebagai berikut:

a. Dari hasil identifikasi, diperoleh urutan stakeholder yang berpengaruh penting bagi kelangsungan dan peningkatan prestasi perusahaan mulai dari urutan yang paling tinggi adalah: karyawan, pelanggan, pemilik modal, supplier serta pemerintah dan masyarakat setempat.

b. Dari hasil identifikasi, berhasil dirumuskan strategi, proses dan kapabilitas untuk memenuhi kepuasan dan kontribusi masing-masing stakeholder.

c. Proses perancangan sistem pengukuran kinerja Perusahaan XYZ menggunakan metoda Performance Prism berhasil merumuskan 31 KPI (Key Performance Indicator).

d. Pencapaian kinerja perusahaan secara keseluruhan pada tahun 2004 adalah sebesar $69 \%$ dari yang telah ditargetkan. Indikator kinerja Stakeholder yang menunjukkan kriteria pencapaian baik adalah pemilik modal, supplier serta pemerintah dan masyarakat setempat. Sedangkan untuk indikator kinerja Stakeholder pelanggan dan karyawan menunjukkan kriteria pencapaian sedang.

e. Terdapat empat KPI yang mempunyai kriteria pencapaian buruk sehingga memerlukan tindakan perbaikan dengan segera, yaitu:

- Jumlah keluhan pelanggan

- Jumlah keluhan karyawan yang dapat diselesaikan

- Peningkatan volume produksi yang tidak sesuai target

- Keterlambatan penyerahan laporan ketenagakerjaan ke Dinas Tenaga Kerja dan Transmigrasi.

\section{PUSTAKA}

[1] Neely, A.D., and Adams, C.A.(a). (2000). Perspectives on Performances: The Performance Prism. Centre for Business Performance, Cranfield School of Management, UK

[2] Neely, A.D., and Adams, C.A.(b). (2000). The Performance Prism Can Boost M $\mathcal{E} A$ Success. Centre for Business Performance, Cranfield School of Management, UK

[3] Neely, A.D., and Adams, C.A.(c). (2000). The Performance Prism in Practice, Centre for Business Performance, Cranfield School of Management, UK.

[4] Neely, A.D., M. Kennerly. (2000). The New Spectrum: How The Performance Prism Frameworks Helps, Centre for Business Performance, Cranfield School of Management, UK 
[5] Neely, A.D., and Adams, C.A.(c). (2001). Managing With Measures In A DownTurn, Centre for Business Performance, Cranfield School of Management, UK

[6] Neely, A.D., Adams, C.A, and M. Kennerly. (2003). The Performance Prism : The Scorecard for Measuring and Managing Business Success. Centre for Business Performance, Cranfield School of Management, UK.

[7] Kaplan, R.S. and Norton, D.P. (1992), The Balanced Scorecard - measures that drive performance, Harvard Business Review, January-February, pp. 71-9 